\title{
Current vulnerability in the Virunga landscape, Rwanda
}

\author{
Charlotte Pavageau' ${ }^{1}$, Ruth Butterfield ${ }^{2}$ and Anne Marie Tiani ${ }^{1}$
}

Between 2011 and 2012, a regional baseline assessment to analyse vulnerability was conducted in five landscapes of the Congo Basin as part of the 'Climate Change and Forests in the Congo Basin: Synergies between Adaptation and Mitigation (COBAM)' project. This briefing note summarises the results for the Virunga landscape around Volcanoes National Park in Rwanda along the borders of Uganda and the Democratic Republic of the Congo (DRC).

\section{Study site in the Virunga landscape}

Several national parks have been established in this area because of the unique and diverse ecosystems. Among them, Virunga National Park (772 700 ha), and Volcanoes National Park in Rwanda (16 000 ha), which were established as a result of transboundary cooperation, constitute some of the oldest protected area in Africa.

The Virunga landscape covers an area of $15155 \mathrm{~km}^{2}$. Most of the land outside the protected areas is used for agriculture. In addition to subsistence agriculture, coffee, tea, cocoa and pyrethrum plantations are prominent land uses, with grasslands making up a small percentage of the area. The population density of the landscape is, at 600 individuals per $\mathrm{km}^{2}$, one of the highest in the region. Factors contributing to this high population density are migration to the area, which began in the 1960s with people attracted by fertile soils, and reduced mortality rates.

Volcanic highland mountains in Volcanoes National Park shelter the last of the world's mountain gorillas (Gorilla beringei beringei) as well as chimpanzees, golden monkeys, forest elephants and a rich variety of birds, reptiles and amphibians. Historically, various institutions have supported the conservation of this rich biodiversity. A consortium of four NGOs (World Wide Fund for Nature, Wildlife Conservation Society, SNV Netherlands Development Organisation, and African Wildlife Foundation/ International Gorilla Conservation Programme) was created to promote sustainable forest management and land use planning. In addition, community-based resource management areas have been implemented in the DRC and Rwandan areas of the landscape. Despite some progress, forest resources are under threat and natural forest management continues to face many challenges, particularly high population pressure.

This study focused on 12 sectors of four districts (Burera, Musanze, Nyabihu and Rubavu) adjacent to Volcanoes National Park in the western and Northern provinces of Rwanda.

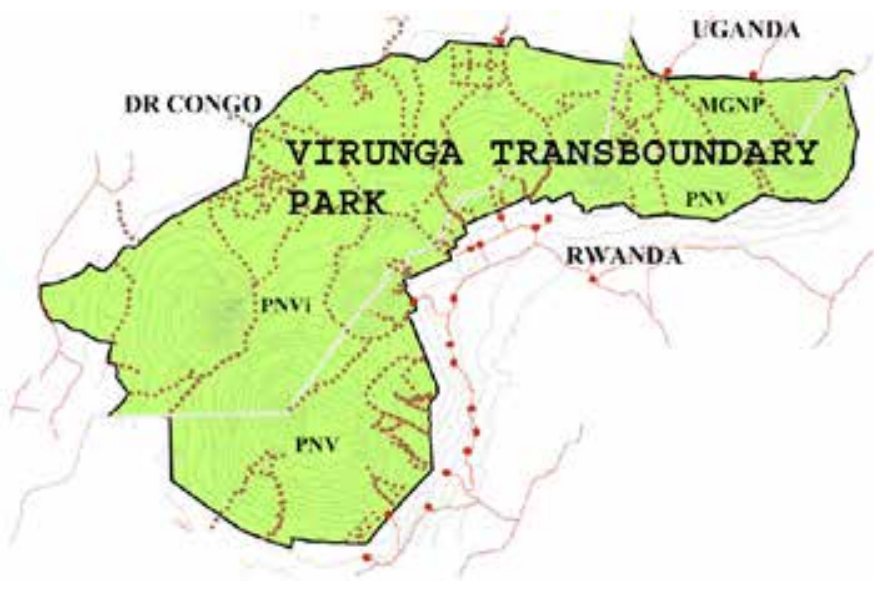

Figure 1. Map of Volcanoes National Park

\section{Participatory methodology}

The vulnerability assessment focused on current vulnerability, which includes an analysis of both past trends and present conditions. In particular, the analysis considers the social aspects of vulnerability, understanding it as a process rooted in the actions of human actors and their interactions with the natural resource base on which they depend.

The methods used to generate information for the various vulnerability dimensions include literature reviews, historical analysis of climate and hazards and, most importantly, participatory workshops. As different groups can display differentiated vulnerability, the analysis was differentiated by gender and by community groups. Workshops were conducted with three groups: one at the district level with local authorities and decision-makers, and two at the local level gathering communities with different ethnic compositions (Batwa and non-Batwa groups). For each group, representatives were gathered from all districts adjacent to Volcanoes National Park.

\section{Local perceptions of change}

Local perceptions were captured during focus group discussions that aimed to explore changes from the 1970s to the present. The inclusion of older people in the participatory exercises made it possible to go back at least two generations. This was important in order to understand the multiple threats that may 
have affected the villages in the past, as well as processes of change in terms of coping mechanisms, social dynamics (e.g. formation of social networks and/or institutions) and ecological dynamics (e.g. degradation or maintenance of biodiversity and ecosystem services).

Among historical disturbances, participants highlighted conflicts and political and social changes because of their impacts on famine, overexploitation of natural resources and livelihoods. They noted that the mass exodus of hundreds of thousands of refugees took its toll on the environment.

It was noted that the re-establishment of the community justice system - the Gacaca court for crimes committed during the genocide - had many implications for social organisation in communities and indirect impacts on land rights and access. In addition, the National Unity and Reconciliation Commission of Rwanda through inter-community exchanges and consultations has sought to redress past discrimination and injustices among community groups. The women's group also mentioned the revision of the matrimonial code, which removed many restrictions on women's access to work and rights to ownership.

\section{Differentiated vulnerability}

The analysis shows that different climate-related disturbances affect different groups, natural resources and activities differently.

For agricultural activities, the impacts on the soil (e.g. removal of arable land following landslides), on plants (e.g. uprooting or damage of growing plants) and on production were differentiated through a participatory exercise with a group of non-Batwa women. The results showed that the direct consequences of an event, such as flooding of the fields hampering access and work in the field, can be mitigated, thus leading to smaller final impacts on well-being or income.

Problems caused by climatic variability tend to be compounded by mismanagement. Heavy rains certainly contribute to the degradation of arable lands, but the use of rudimentary cultural techniques is an important factor in erosion. Soil erosion on steeply sloping land results in water flows and siltation of lakes, rivers

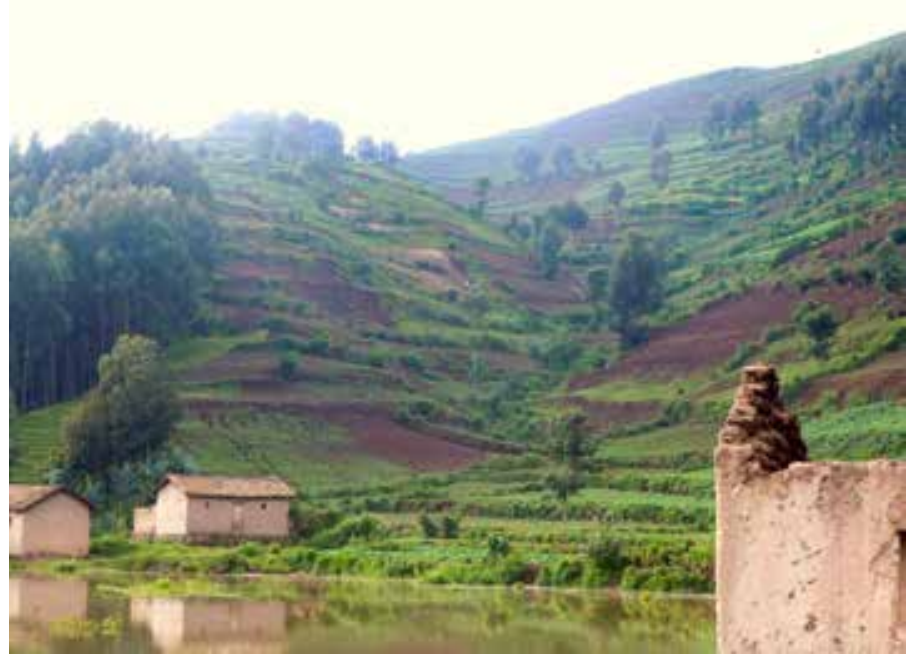

Erosion of soil on steeply sloping land and swamps, but heavy rains are only an indirect cause. Indeed, erosion is largely attributable to the practice of cultivating steep slopes without applying methods of soil conservation, soil and water management, organic and mineral restitution and avoidance of overexploitation. The continuous degradation of the area and decline in soil fertility constitute one of the main concerns of participants.

The results show that Batwa groups perceive themselves as being more severely affected by destructive disturbances, such as strong winds, which destroy houses, fields and produce, compared with non-Batwa groups. The community-based natural resource management plan identifies the Batwa as a distinct group around the park for 'their extreme poverty compared to the other members of the community, and the magnitude of their dependency on and interaction with the park'. Moreover, the restriction of access to the park has led to the displacement of those communities living outside of the park. Despite a few initiatives to rehouse them, most of the Batwa live in poor and flimsy housing.

Floods also tend to have more severe impacts on agriculture for this group, largely because of their poorer access to good-quality and less exposed land. For example, these groups'lands are concentrated on steeper slopes or lower-lying areas. This group also appeared to be less sensitive to reductions in fodder for livestock but more sensitive to disruptions of wild honey production during the prolonged dry season. A higher dependence on natural resources and lower dependence on livestock contribute to these differences. Other studies show that Batwa around Volcanoes National Park have the least livestock of all groups, owning on average 1.04 animals compared with 2.73 for other groups in the community.

\section{Dynamics of ecosystems}

Volcanoes National Park constitutes almost the only reservoir of forest biodiversity in the area. The restriction on uses imposed by the park limits the interactions between the communities and the forest. However collection of certain forest products (wild honey, mushrooms) and water gathering are allowed. People also exploit

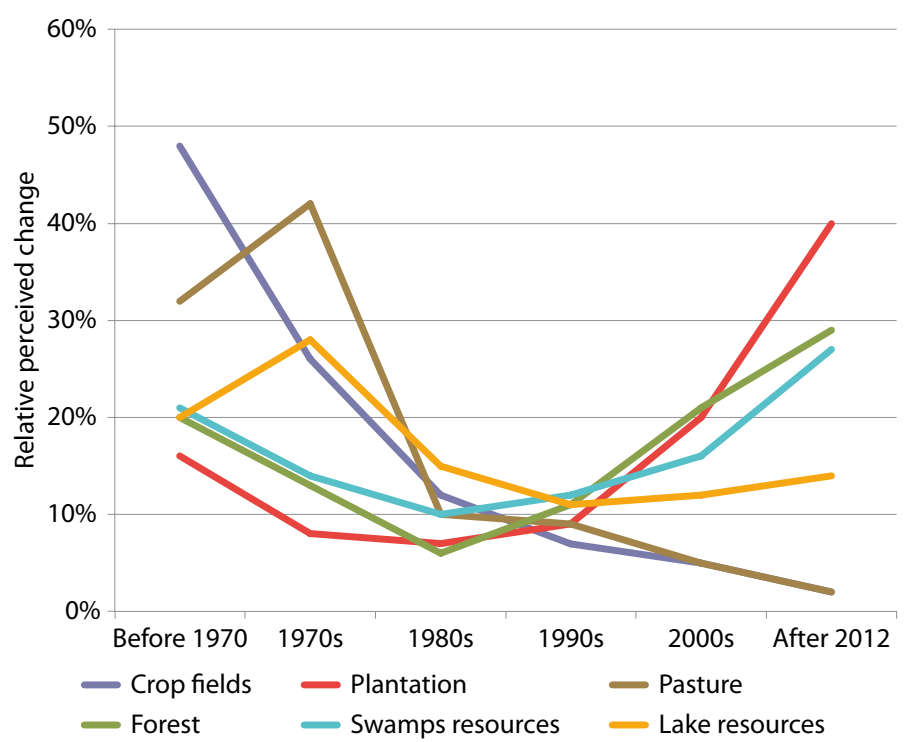

Figure 2. Participants' perceptions of trends in changes to land use and other resources 
Table 1. Use and benefits of each land use type

\begin{tabular}{|c|c|c|c|c|c|c|}
\hline Land use type & Food crops & Cash crops & Forest (Park) & Swamp & Pasture & Lake \\
\hline \multirow[t]{6}{*}{ Products } & Potatoes & Pyrethrum & Wild honey & Products for & Fodder & Fish \\
\hline & Beans & Tea & Softwood & reeds and mats & & Hydroelectric \\
\hline & Peas & & Fuelwood & Sand, stones & & energy \\
\hline & Maize & & Bamboo stick & & & \\
\hline & Wheat & & & & & \\
\hline & Vegetables & & & & & \\
\hline \multirow[t]{4}{*}{ Benefits } & Nutrition & Revenue & Nutrition & Revenue & Nutrition & Nutrition \\
\hline & & & Construction & Materials & & Energy \\
\hline & & & Energy & & & \\
\hline & & & Revenue & & & \\
\hline
\end{tabular}

the resources illegally for poaching, bamboo harvesting, fuelwood harvesting, medicinal plant collection and grazing. Dependency on the park resources is higher for Batwa groups. In particular, 28.8\% of the Batwa households stated that they collect fuelwood from the park, compared with only $0.4 \%$ of the rest of the community. Nevertheless, exploitation in the park seems to have decreased in recent years because of a reinforced conservation programme and interventions initiated with communities.

Land uses in the region have changed rapidly in recent decades. Perceived changes in land use since 1970 are depicted in the Figure 2. The main drivers of the perceived changes were the demographic evolution, waves of migration and side-effects of the civil war.

\section{Current adaptive capacity}

The landscape is mainly domesticated and natural forest resources do not make a major contribution to local livelihoods. Most of the safety nets during periods of stress are developed outside the forest through efforts to diversify activities. Infrastructure, land use planning and domestication of the landscape constitute other main responses to the stresses (e.g. use of terracing, channelling of water flows, improvements to roads, installation of water tanks). These initiatives are generally supported by public policies or external actors, mainly development agencies.

The gorilla-based conservation scheme has been a tremendous factor behind economic development in the region and is largely held up as a success story in Africa. Increased devolution of authority to the local level and shifting of responsibility to local communities have contributed towards the strengthening of adaptive capacity in the region. Some of the solutions to climatic stresses that participants referred to, such as installation of water tanks, were supported by the redistribution of tourism revenues from the park to local communities. However, the level of returns for the local population is not equivalent to the increasing population pressure, lack of opportunities for most of the population and poverty. Rather, this new economic development has mainly benefited tourism investors and well-connected cooperatives. Restrictions on access to natural resources and poor access to land for marginalised groups have actually increased their vulnerability.

The management of natural resources remains a highly centralised process that is mainly implemented through restriction of access and top-down regulation (conservation approach, state plantations). However, this approach has failed to prevent uncontrolled exploitation of resources, including park resources, which exacerbates the vulnerability of the population. For example, poorer households still depend heavily on wood for energy and medicinal plants. Policies to preserve these resources are weak; for example, there are no policies to protect water sources, rivers and ravines or regulate mineral exploitation. Another example is the rule that only an area of forest less than 0.5 ha can be logged without authorisation, which has led to misuse of forest ecosystems in the context of a scattered forest landscape. The analysis highlighted that actors at all levels recognise the importance of trees as a buffer against hazards.

\section{Looking ahead}

Possible approaches to improve adaptive capacity include fostering agroforestry and restoring abandoned lands. However, as the shortage of available land prevents the establishment of large plantations, strategies need to be developed for marginal lands, and would then require coordination of multiple individual activities. The selection of appropriate species that are compatible with agricultural production could generatebenefits for individuals and incentives to conserve trees. Possible strategies would be to introduce mechanisms to reduce overexploitation of fuelwood (e.g. promotion of sustainable harvesting planning and assisted natural regeneration techniques in existing plantation) and to encourage transformation and valorisation of residues.

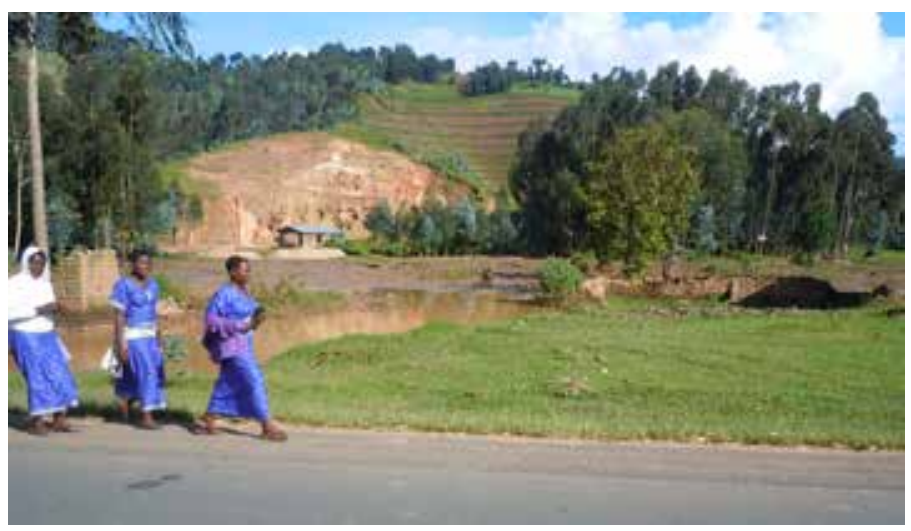

Introducing more trees into the farmed landscape would assist the landscape in coping with climate change 
Pilot projects, such as those supported by the COBAM project, could lay the foundations for longer-term solutions, as long as there is systematic learning that enables reflection and refinement along the way. This will require mechanisms to support the learning process and enable experimenting, monitoring and improving over time.

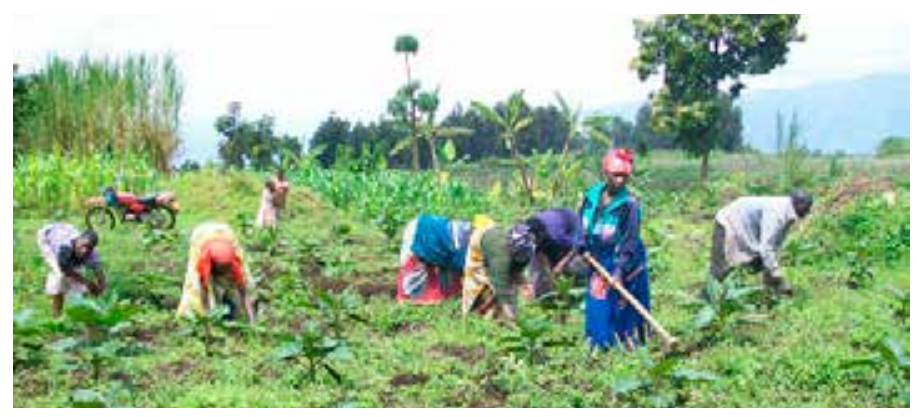

Members of a women's cooperative at work in a collective field
The insights generated through the vulnerability baseline assessment in the Virunga landscape will be combined with more in-depth research to explore future vulnerability and to identify synergies between mitigation and adaptation in the project sites. Results from further analyses and evaluation of future strategies will be used to generate recommendations to inform decision-making and planning at local and national levels across countries in the Congo Basin.

\section{Acknowledgements}

The regional baseline assessment was implemented in collaboration with many partners. Researchers from the Stockholm Environment Institute (SEI) and the Center for International Forestry Research (CIFOR) worked closely with local partners in each site. In the case of the Virunga landscape, we would like to thank Dancilla Mukakamari, Innocent Bizimana, Jean-Pierre Mugabo and the rest of the team at ARECO for the support provided.
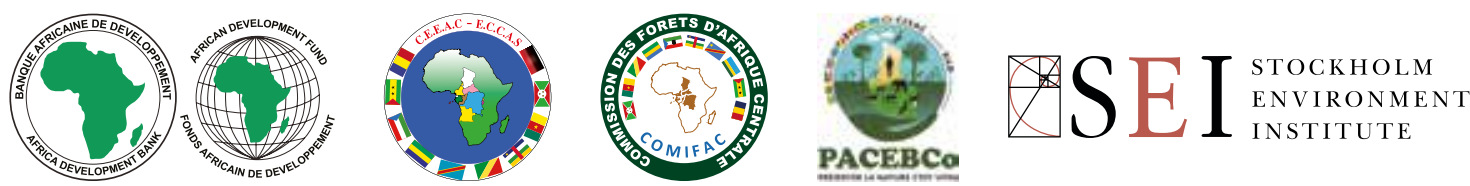

\section{cifor.org/cobam}

blog.cifor.org

\section{Center for International Forestry Research}

CIFOR advances human wellbeing, environmental conservation and equity by conducting research to inform policies and practices that affect forests in developing countries. CIFOR is a CGIAR Consortium Research Center. CIFOR's headquarters are in Bogor, Indonesia. It also has offices in Asia, Africa and South America. 